\title{
LA REAL EXPEDICIÓN FILANTRÓPICA DE LA VACUNA EN CANARIAS \\ (9 de diciembre de 1803 - 6 de enero de 1804)
}

\author{
Víctor García Nieto \\ Hospital Universitario N. S. de Candelaria. Santa Cruz de Tenerife \\ Justo Hernández
}

Facultad de Medicina. Universidad de La Laguna

\section{RESUMEN}

Se han estudiado las circunstancias y consecuencias de la escala de la Real Expedición Filantrópica de la Vacuna (1803-1806) en el Archipiélago Canario. Nos hemos centrado en los relatos de testigos canarios más que en los datos burocráticos y administrativos. Tenemos constancia de la difusión de la vacuna en las islas. Finalmente, hemos puesto de relieve el papel determinante y decisivo de la Iglesia en la consecución de los objetivos de la Real Expedición.

PALABRAS CLAVE: vacuna, expedición, Tenerife, Gran Canaria, Lanzarote, La Palma.

\section{SUMMARY}

The conditions, circumstances and aftermath of the stay of the Balmis' Royal Vaccinal Expedition (1803-1806) in the Canary Islands have been studied in this paper. We have focused on reports from canary witnesses rather than official and administrative data. We have records of the spreading of the vaccine out to the isles. Finally, the decisive and determinant part played by the Roman Catholic Church to achieve the objectives of the Royal Expedition has been remarked.

KEY WORDS: vaccine, expedition, Tenerife, Grand Canary, Lanzarote, La Palma.

\section{INTRODUCCIÓN}

La historiografía sobre la escala de la Real Expedición Filantrópica de la Vacuna (1803-1806), dirigida por el Físico de Cámara de S. M. Francisco 
Xavier de Balmis y Berenguer (1753-1819), en el Archipiélago Canario ${ }^{1}$, se ha basado, en líneas generales - y sin descuidar otras fuentes - en los datos proporcionados por el Archivo General de Indias (AGI) y por la Gaceta de Madrid $^{2}$. Nosotros, sin preterir las otras informaciones, centraremos nuestra atención en lo que nos cuentan los propios testigos canarios, coetáneos de la arribada y estadía de la Real Expedición. Y fundamentalmente por tres motivos. De una parte, para intentar satisfacer el anhelo que expresa una nota final de uno de los expedientes del Archivo General de Indias:

Se echa de menos en el expediente todo lo perteneciente a la llegada de Balmis a Canarias, el Reglamento para la Junta Central de Vacuna y demás tareas de la Expedición en dichas islas ${ }^{3}$.

De otra, porque los datos han sido consignados por los burócratas de la Corona a más de $2.000 \mathrm{kms}$. de Canarias, es decir, ab extra de Canarias y preciso es retomar la historia ab intra de Canarias, a partir de lo que nos narran los canarios en y desde Canarias. En suma, se trata de dar una visión más intrahistórica de lo que fue y supuso la visita de la Real Expedición en Canarias. Finalmente, para sazonar y endulzar el formalista y oficial dato administrativo y burocrático con la lozanía y frescura del relato de lo visto, oído y vivido.

1 Dos son a nuestro juicio los trabajos fundamentales sobre el tema: BÉTHENCOURT, A. de, «Inoculación y vacuna antivariólica en Canarias (1760-1830)», en MoRALES, F., ed., (1985), V Coloquio de Historia Canario-Americana (1982), vol. II, Madrid, Ediciones de la Excma. Mancomunidad de Cabildos de Las Palmas de Gran Canaria y del Excmo. Cabildo Insular de Gran Canaria, pp. 281-307; y RAMíREZ, S. (2001), «La vacuna o el patriotismo lanzaroteño», Cuadernos del Ateneo de La Laguna, $\mathrm{n}^{\mathrm{o}}$ 10, 188-201. Sobre la Real Expedición en conjunto, $c f$. DíAZ DE YRAOLA, G. (1948), La vuelta al mundo de la expedición de la vacuna, Sevilla, Escuela de Estudios Hispanoamericanos; RAMíREZ, S. (2002), La salud del Imperio. La Real Expedición Filantrópica de la Vacuna, Madrid, Doce Calles/Fundación Jorge Juan; y Balaguer, E. y BALlester, R. (2003), En el nombre de los niños. La Real Expedición Filantrópica de la Vacuna (1803-1806), Madrid, AEP-Wyeth. Este último libro cuenta también con una edición electrónica: www.aeped.es/balmis/libro-balmis.htm. Por último, es muy útil el portal de internet de la Fundación Francisco X. Balmis y del Rotary Club de Alicante: www.balmis.org.

2 BALAGUER y BALLESTER (2003), p. 132.

3 Expediente 11. Extracto General de la Expedición filantrópica de la Vacuna. AGI, IG, 1558-A. Tomado de RAMíreZ (2001), n. 12, p. 200. 


\section{PROLEGÓMENOS}

Como importante detalle previo a los preparativos de la llegada de la Real Expedición, conviene señalar que Canarias conocía ya el método de Jenner y lo había puesto en práctica con éxito. Nos lo cuenta el propio III Vizconde del Buen Paso, Don Juan Primo de la Guerra, natural de La Laguna:

Mi madre ha hecho vacunar al chico de la criada Nicolasa, le hizo la inoculación y le ha asistido don Domingo Saviñón. Se le han presentado tres viruelas mayores que las comunes, y que forman debajo un tumor de alguna consistencia. Ha seguido su curación con la misma felicidad que los demás niños del país, en quienes se ha ejecutado este descubrimiento ${ }^{4}$.

Y también nos dice el portuense Don José Álvarez Rixo, alcalde del Puerto de la Cruz de La Orotava (actual Puerto de la Cruz) en diversas etapas que

trájose a este Puerto el pus de la vacuna por primera vez en dicho año de 1803 , por suscripción de los vecinos pudientes, vacunándose trescientos noventa y cinco niños, antes que la hubiese remitido nuestro Soberano... y se continuó esta benéfica operación en abril de año siguiente de $1804^{5}$.

En relación con los pasos previos de la Real Expedición y en lo que afecta a nuestro Archipiélago, consta que en el proyecto de Balmis, aprobado el 23 de junio de 1803 y titulado Derrotero que debe seguirse para la propagación de la vacuna en los dominios de Su Majestad en América se contaba con difundir la vacuna en las Islas Canarias:

En un paquebot destinado a este fin se saldrá del puerto de La Coruña, dirigiéndose a la Isla de Tenerife, llevando vacunado a uno de los niños que han de ir a este objeto para establecer en ella la práctica de la vacunación, y que pueda propagarse a las restantes Islas Canarias ${ }^{6}$.

4 Primo de la Guerra, J. (1976), Diario I. 1800-1807, Madrid, Aula de Cultura de Tenerife, p. 201, (Martes, 2 de agosto de 1803).

5 ÁlvareZ, J. Memorias de los sucesos más memorables acaecidos en el Puerto de La Orotava en este siglo XIX, cap. III, manuscrito. Citado por BÉTHENCOURT (1985), n. 25, p. 286.

6 Instrucción del 23 de junio de 1803 firmada en Aranjuez por la Junta de Cirujanos de Cámara y dirigida al Ministro de Gracia y Justicia, Don José Antonio Caballero. Tomado de BALAGUER y BALLESTER (2003), fig. 12, p. 110. 
Además, en una Real Orden, por la que se anuncia la Real Expedición, se insta al recién nombrado Comandante General de Canarias, el Mariscal de Campo Don Fernando Cagigal de la Vega, Marqués de Casa Cagigal, a que

\footnotetext{
procurase persuadir con su ejemplo al buen recibimiento de la expedición... dando las disposiciones que le dictase su celo, comunicando a su tiempo lo que resultase ${ }^{7}$.
}

Don Fernando se convierte en el director de operaciones. Deberá conseguir vacunar el máximo número de personas, en especial las pertenecientes a las clases más menesterosas y numerosas, durante la estadía de la Real Expedición en el puerto. Conservará y distribuirá algunos vidrios de linfa vacunal por el Archipiélago, repartiendo unos pocos ejemplares del libro traducido por Balmis ${ }^{8}$. Cagigal orquestó una eficaz campaña de mentalización y propaganda. Reunió a las autoridades de la isla en su propio palacio y, fruto de esta junta, se decidió invitar a los cabildos de las distintas islas para que prepararan con tiempo todo lo necesario. Pidió al cabildo de La Laguna que pagase el alquiler de una inmueble en condiciones - será la futura casa de vacunación-, digno y capaz de alojar y mantener a los niños y al equipo sanitario de la expedición 9 . Dicha casa se ubicará en Santa Cruz para que en el futuro se haga cargo el médico del Hospital Militar en lo tocante a la vacunación. El cabildo encargó a los regidores Don Francisco de Tolosa y Don José de Monteverde que preparasen todo lo necesario ${ }^{10}$.

Unos días más tarde volvió Don Fernando a convocar en su palacio a todas las autoridades y notables isleños, dictando un discurso patriótico, exhortando a desechar cualquier desconfianza del pueblo, teniendo en cuenta

que sus ideas y conocimientos están muy lejos de ver el bien; y las innovaciones jamás fueron bien admitidas. La costumbre manda al común de los hombres y casi siempre tenemos por mejor lo que practicaron nuestros abuelos ${ }^{11}$.

7 Real Orden del 1 de septiembre de 1803. AGI, IG, 1558-A. Citado por BALAGUER y BALLESTER (2003), p. 112, n. 79.

8 BÉTHENCOURT (1985), p. 287. Se refiere a MoREAU, J. L. (1803), Tratado histórico y práctico de la vacuna, Madrid, Imprenta Real.

9 Carta del 20 de octubre de 1803 al Cabildo de La Laguna. Tomado de BÉTHENCOURT (1985), n. 26, p. 287.

10 BÉTHENCOURT (1985), p. 287.

11 Ibid., pp. 287-288, n. 29. 
Emitió además un bando que fue profusamente difundido, cuyo comienzo rezaba así: «Pueblos de todas ellas (las islas) corred a presentar vuestros inocentes hijos a los brazos de la salud... $\rangle^{12}$. Dicho bando, impreso en gran formato y expuesto en los lugares acostumbrados, sobre todo en las puertas de las iglesias y en los mercados, exhortaba a que se mandasen los niños para ser vacunados, encomiando y explicando la importancia y trascendencia de las vacunaciones ${ }^{13}$.

Sólo tenemos datos fehacientes que nos hablan de que la vacuna llegó a las islas de Tenerife, Gran Canaria, Lanzarote y La Palma, aunque en un informe de la Junta Superior de Medicina se afirma que alcanzó a las siete islas del Archipiélago Canario ${ }^{14}$. A continuación nos detendremos en los pormenores y avatares acaecidos al respecto en las cuatro islas citadas más arriba.

\section{TENERIFE}

Al atardecer del día 9 de diciembre de 1803 la corbeta María Pita, de 160 toneladas de desplazamiento, enfilaba la rada del puerto de Santa Cruz de Tenerife, fondeando en torno a las 20 horas $^{15}$. La bienvenida fue calurosa y entusiasta, pues fue

recibida con el mayor aplauso por aquellos habitantes, estimulados del ejemplo y exhortaciones del Comandante General de Canarias Marqués de Casa-Cagigali ${ }^{16}$.

Así lo relata Antonio de Béthencourt:

En medio del entusiasmo general, el Marqués de Casa-Cagigal recibe con ternura en el embarcadero el primero de los niños coruñeses. El resto de las autoridades, por estricto orden jerárquico, repetían hasta 22 veces la operación. Fueron rendidos honores militares a la expedición y se organiza una comitiva para dirigirse a la casa habilitada. El cortejo, amenizado por la banda de música del Batallón

12 Bando del 17 de noviembre de 1803. Citado por BÉTHENCOURT (1985), n. 30, p. 288.

13 Cioranescu, A. (1998), Historia de Santa Cruz de Tenerife, vol. II, 1494-1803, Santa Cruz de Tenerife, Caja de Canarias, n. 54, p. 354. Vid. COLA, L. (1996), Santa Cruz de Tenerife, bandera amarilla. Epidemias y calamidades (1494-1916), Santa Cruz de Tenerife, Ayuntamiento, p. 136.

14 Balaguer y Ballester (2003), pp. 132-133.

15 Gaceta de Madrid, viernes 20 de enero de 1804. Tomado de RAMíREZ (2001), n. 1, p. 189.

16 Informe de la Junta Superior de Medicina de 26 de mayo de 1804. AGI, IG, 3163. Citado por RAMíREZ (2001), n. 2, p. 189. 
de Canarias, avanzaba en medio de vivas y aplausos, cohetes y las salvas del Castillo principal. Ceremonia y alegría fueron compatibles esta vez con eficacia: a pesar de ser noche cerrada, una hora más tarde estaban vacunados diez niños pertenecientes a las mejores familias ${ }^{17}$.

Entre las varias causas de este buen recibimiento, pueden sugerirse al menos dos: se conoce ya la vacuna jenneriana en el Archipiélago y el clima ilustrado de las autoridades tanto civiles como eclesiásticas es elevado, superior tal vez al propio de la península ${ }^{18}$. Y como prueba de nuestros asertos recogeremos aquí un soneto que compuso uno de los grandes ilustrados tinerfeños, Don José Viera y Clavijo:

Carlos Cuarto, Gran Rey, pues que es humano forma una expedición, jamás oída, que asegure a sus súbditos la vida, y extirpe el cruel imperio de un tirano.

Quiere que corra el mundo americano y haga escala en Canarias á la ida: de niños es la tropa, que aunque herida, la pólvora inmortal lleva en un grano...

A Santa-Cruz llega el baxel triunfante, y Casa-Cagigal, que la fortuna del hombre y de las islas hizo amante.

Con la solemnidad más oportuna, Saca en sus brazos al primer infante, y enseña rendir cultos a Vacuna $^{19}$.

Dejemos ahora que los contemporáneos canarios nos cuenten sus impresiones sobre las actividades de la Real Expedición. Álvarez Rixo nos dice que

será este año memorable en los anales de este pueblo y de los demás de esta Provincia por haber llegado a Santa Cruz el 10 de diciembre la Corbeta Española

17 BÉTHENCOURT (1985), p. 288.

18 Cf. Hernández, M. (1987), La Ilustración en Canarias, La Laguna, Centro de la Cultura Popular Canaria; y Hernández, M. (1998), Ciencia e Ilustración en Canarias y Venezuela: Juan Perdomo Béthencourt, La Laguna, Centro de la Cultura Popular Canaria.

19 Tomado de Guigou, D. M. (1945), El Puerto de la Cruz y los Iriarte (Datos históricos y biográficos), Santa Cruz de Tenerife, A. Romero, pp. 69-70. 
María Pita enviada por S. M. el Rey Carlos IV y su ministro don Manuel Godoy ${ }^{20}$, quién tomó mucho empeño en esta expedición, con varios médicos y diez niños vacunados para establecer y propagar la vacuna en estas Islas ${ }^{21}$.

El testimonio de Primo de la Guerra, coetáneo estricto de la escala de la Expedición, es más jugoso:

Mi hermana me dice en carta de hoy de haber llegado al mismo puerto el correo de España y de hallarse todavía en Santa Cruz la expedición de niños que de orden del rey pasan a la América para que se propague la inoculación de la vacuna. Los niños mencionados, que son veintidós, fueron recibidos con varios honores militares y la música del batallón. Además de ser correspondientes estos obsequios a las circunstancias de esta empresa, el comandante general se habrá prestado a ellos con la complacencia que le es propia en los actos de beneficencia y humanidad ${ }^{22}$.

Viendo Balmis la entusiasta colaboración de los tinerfeños, se ofreció a subir a vacunar a La Laguna, para evitar que padres e hijos tuviesen que bajar hasta Santa Cruz. Pero estuvo todavía varios días en Santa Cruz vacunando a destajo $^{23}$. ral:

Prosigue Primo, hablándonos del bando dictado por el Comandante Gene-

Yo fui a La Laguna el sábado próximo por la tarde, creyendo ver en dicho pueblo las personas que componen la expedición de la vacuna; pero éstas permanecen en Santa Cruz. Ayer se fijó en las plazas principales de la ciudad un bando del comandante general convocando a los habitantes de las islas a participar de este beneficio. Contiene una relación circunstanciada del destino de la expedición y del amor paternal con que el soberano se ha dignado enviarla a sus expensas. Las expresiones en que está concebida son dictadas por el mismo jefe. El marqués de Villanueva me ha regalado un ejemplar de este bando ${ }^{24}$.

20 La historiografía oficial relativa al reinado de Carlos IV ha sido injusta con Godoy. Vid. LA PARRA, E. (2002), Manuel Godoy. La aventura del poder, Barcelona, Tusquets.

21 Álvarez, J. A. (1994), Anales del Puerto de la Cruz de La Orotava, 1701-1802, Santa Cruz de Tenerife, Cabildo Insular de Tenerife-Ayuntamiento del Puerto de la Cruz, p. 178. Álvarez Rixo contaba siete años de edad cuando aconteció la arribada del Maria Pita, por lo que yerra en dos detalles: el barco llegó el día 9 y los niños eran 22.

22 PRIMO (1976), p. 221 (Lunes, 12 de diciembre de 1803).

23 BÉTHENCOURT (1985), p. 288.

24 PRIMO (1976), p. 221 (Lunes, 19 de diciembre de 1803). 
Y nos explica que el 26 de diciembre subieron a La Laguna los médicos del equipo de Balmis:

En efecto subieron ayer por la mañana los médicos españoles [peninsulares] de la expedición. Hubo en todo el día un numeroso concurso de niños que fueron vacunados, llevando los españoles [peninsulares] apuntados el nombre de cada uno, sus padres y el lugar de nacimiento. No subió ayer el director Balmis, a quien se espera hoy que es el día destinado para función de iglesia ${ }^{25}$.

\section{Cuenta que ha tenido en sus manos el tratado de Moreau, traducido por Balmis:}

He visto un tratado de la vacuna escrito en francés y traducido al castellano por el director de la expedición philantropica don Francisco Javier de Balmis. Es una colección de las experiencias hechas sobre este descubrimiento. La historia de su invención, reflexiones sobre sus utilidades y la práctica de su inoculación. Contiene los prólogos del autor y del traductor, el retrato del doctor Eduardo Tenner (sic), descubridor de la vacuna en el condado de Gloucester y una estampa que representa el carácter y progresos de estas viruelas, impreso el libro en Madrid en el presente año ${ }^{26}$.

\section{Nos relata además una interesante y gráfica anécdota:}

También he oído leer una carta del ciudadano Gros que en el día hace en estas islas las funciones de comisario de relaciones comerciales de la Francia, pidiendo al comandante general el permiso para vacunar a una niña, hija del ciudadano Marcelin, y elogiando al mismo tiempo con expresiones enérgicas y elevadas el importante objeto de la expedición y la gloria que de ella resulta al soberano que tanto se complace en difundir por sus dominios el beneficio de la vacuna. Acompaña a esta carta la contestación del general que, ofreciendo al comisario avisarle el día en que pueda inocularse la hija de Marcelin, le regala un ejemplar de la mencionada obra y al paso que reconoce cuán fundadas son las alabanzas de Gros en aplauso de la expedición de la vacuna, le da de ella una idea más amplia, presentando los puntos geográficos y remotos adonde la nave conduce a su bordo los niños y profesores que depositan el benéfico secreto, recorriendo de paso otros vastos proyectos que en diversos tiempos se encuentran en la historia de la nación española a los cuales se aventaja el presente que, mientras la Inglaterra y la Francia se aprestan para derramar sangre y difundir el terror y la guerra, éste sólo trata de conducir la salud y la vida ${ }^{27}$.

25 Ibid., p. 222 (Martes, 27 de diciembre de 1803).

26 Ibid., p. 222, (Miércoles, 28 de diciembre de 1803).

27 Ibid., pp. 222-223 (Miércoles, 28 de diciembre de 1803). 
Y pasa a narrarnos la solemne celebración litúrgica del día 27 de diciembre, fiesta de San Juan Apóstol y Evangelista, en la Iglesia de La Concepción de La Laguna:

Ayer subieron de Santa Cruz el director don Francisco Javier de Balmis y el capitán de puerto don Carlos Adam. Celebróse con toda solemnidad en la parroquial de la Concepción la función de San Juan Evangelista y de acción de gracias por la expedición. Concurrió el ayuntamiento, comunidades religiosas, hermandades y largo número de personas del pueblo. Llevó el guión en la procesión del Sacramento el director Balmis, quien tiene buena presencia y aspecto agradable y se adornaba con el uniforme de su clase, que es azul y encarnado con bordados de oro, ancho y brillante, y asistió a la función presidiendo el cuerpo de los facultativos españoles [peninsulares], quienes se presentaron también con uniforme azul y encarnado, con galón de plata. Predicó el padre Fray Gregorio, franciscano, quién después de haber hecho el elogio de San Juan por su primacía entre los escritores sagrados y por los beneficios de su intercesión a favor de los hombres, celebró las conveniencias del reciente preservativo de las viruelas, pidiendo a Dios por sus progresos y felicidad de la expedición ${ }^{28}$.

Pero como todas las grandes fiestas se celebran in missa et in mensa, a continuación tuvo lugar un suculento banquete sufragado por el Cabildo, al que asistieron los grandes notables tinerfeños:

El Cabildo hizo un largo convite en la casa de Mesa, a que concurrieron el gobernador de las armas, conde de Sietefuentes; el corregidor, el regidor decano don Lope de la Guerra, el personero general don Bartolomé González de Mesa y otros regidores y diputados del cabildo; el vicario don Josef Martínez de Fuentes; el beneficiado don Antonio Villanueva, quién cantó la misa de la función; el predicador, los marqueses de Casahermosa, de Villanueva del Prado y de la Fuente de Las Palmas, el prior del Consulado, don Juan Próspero de Torres; don Fernando del Hoyo, señor de la villa de Santiago; el castellano don Josef de Monteverde; don Lorenzo Montemayor, subdelegado del Real Protomedicato; don Domingo Saviñón y otros oficiales y paisanos cuyo número casi llegaría a cuarenta personas. El regidor don Juan Tavares leyó en la mesa una oración gratulatoria, escrita por uno de los profesores españoles [peninsulares] a los obsequios y atenciones con que la expedición ha sido recibida en el país y se brindó por el rey, por el comandante general, por el Cabildo, por la expedición y demás atenciones del día. El director Balmis, antes de comer, como profesor, como traductor del Tratado de la vacuna y como encargado verbalmente por los reyes del éxito de esta empresa, presentes los que están nombrados, hizo de ella en conversación una exposición circunstanciada

28 Ibid., pp. 223 (Miércoles, 28 de diciembre de 1803). 
que por todos fue oída con sumo gusto. Elogió al profesor don Domingo Saviñón, a cuya instrucción y conocimiento dijo que podrá dejar confiada la continuación y conservación de la vacuna en esta ciudad. Allí habló de este descubrimiento desde su origen en Gloucester hasta su actual estado, las contradicciones que ha sufrido y la importancia de su práctica, el derrotero de la embarcación y la ternura con que los reyes aún con lágrimas pusieron a su cuidado el desempeño de este encargo, siendo su voluntad que se extendiese hasta las Filipinas. Balmis y sus compañeros, poco después de la comida, se volvieron a Santa Cruz, donde los esperaba el comandante general para inoculación de algunos niños que han venido a vacunarse de la isla de Canaria [Gran Canaria]. Yo me hallé a la función de iglesia y permanecí en la casa con los demás convidados hasta la despedida de la expedición ${ }^{29}$.

Hemos visto que en este texto se alude a la llegada de varios niños grancanarios el 27 de diciembre. En efecto, ya desde la llegada de la Real Expedición, Casa-Cagigal pidió que las autoridades de cada isla enviasen a Santa Cruz un grupo de niños para ser inoculados, brazo a brazo, y después garantizar la conservación de la linfa:

haciendo que saliese de cada una algun barco para esta [isla de Tenerife] con niños y facultativos, que volviendo los unos inoculados y los otros instruidos en la práctica de la vacuna la comunicará a sus paisanos ${ }^{30}$.

En nuestro Archipiélago la Real Expedición se financió gracias a «donativos voluntarios del Reverendo Obispo, y las suscripciones del vecindario» ${ }^{31}$. Pero para terminar con las donaciones voluntarias Casa-Cagigal propuso dos soluciones. La primera y más eficaz era

la aplicación de una cantidad determinada de los propios y arbitrios de las siete islas prorrateada a proporción de los fondos de cada una.

\section{La segunda consistía en el}

establecimiento de un juego de lotería quedando sujeta la suerte a las extracciones de Madrid, a cuyo fin ofrece formar un plan, que precava el fraude ${ }^{32}$.

29 Ibid., pp. 223-224 (Miércoles, 28 de diciembre de 1803).

30 RAMíREZ (2001), p. 189.

31 Ibidem

32 Carta del Comandante General de Canarias, fechada en Santa Cruz de Tenerife el 31 de enero de 1804. AGI, IG, 1558-B. Citado por RAmíreZ (2001), n. 6, pp. 189-190. 
Finalmente, se optó por la primera por ser la más sencilla y asequible.

Concluidos ya los extremos relativos a la organización de las pequeñas expediciones a la isla de Tenerife y de la financiación total, volvamos al relato de Primo de la Guerra. Nos dice que

Según me escribe mi hermana, estuvo bien desempeñada la función de acción de gracias celebrada en la plaza de Santa Cruz en el día de Inocentes por la expedición de la vacuna. Dice también que por la noche se puso víctor en la casa del Comandante General ${ }^{33}$.

Y he aquí el víctor, compuesto por Don Pedro Murga, presbítero de Santa Cruz de Tenerife:

A Carlos Cuarto, el Rey más ilustrado

y de la más cordial filantropía,

propagar por el Orbe competía

el remedio de un mal inveterado.

Carlos con el «corpax» en su reinado

de la viruela atroz la tiranía

va a extrañar de su inmensa monarquía,

sin olvidar el suelo afortunado.

Nivaria, pues, consagra su montaña, qual Avila y qual Calpe por coluna

al que de la hidra triunfa y de su saña

y nunca olvidará que la vacuna

se la remite el Hércules de España,

por el jefe en quien funda su fortuna ${ }^{34}$.

Finalmente, el día de Reyes de 1804, la Real Expedición zarpa hacia Puerto Rico:

Se hizo á la vela de esta rada con rumbo á Puerto-Rico la corbeta María Pita, conductora de la expedición marítima de la vacuna, después de haber practicado el Director y demás individuos que la componen, tres operaciones generales en los 27 días que residieron en esta isla ${ }^{35}$.

33 Primo (1976), p. 224 (Sábado, 31 de diciembre de 1803).

34 Ibid., p. 225 (Domingo, 1 de enero de 1804).

35 Gaceta de Madrid, viernes 10 de mayo de 1804. Tomado de RAMírez (2001), n. 9, p. 190. 


\section{GRAN CANARIA}

Casa-Cagigal escribió a la Audiencia y al Cabildo, explicando que podía quedar asegurada la vacuna fresca, conservándose largo tiempo en estas Islas, «si todos contribuimos a ver realizadas las paternales intenciones», por lo que enviaban algunos vidrios con linfa y cuatro ejemplares del tratado de Moreau. Unos cuantos niños fueron enviados desde Gran Canaria con sus padres, como hemos visto más arriba, ocupándose el cabildo lagunero de los gastos ${ }^{36}$. Sin embargo se había rumoreado que los niños no iban a regresar, sacándolos la Real Expedición del Archipiélago. Por lo cual, el Comandante General tuvo que disipar los bulos en una carta para que pudiera organizarse la pequeña expedición, porque

los mal intencionados, los ignorantes, los excesivamente tímidos habían esparcido voces en ocasiones que traen graves perjuicios a la causa pública. Entre otras, como la de que esta Expedición debe llevarse niños de estas Islas. Y ella, aunque es falsa, aterra a los padres que ignoran que S. M. no quiere que se verifique sin su consentimiento $^{37}$.

Se fletó una embarcación para trasladar a Santa Cruz siete niños acompañados de sus padres, los cuales fueron generosamente gratificados por el Obispo Don Manuel Verdugo Albiturría ${ }^{38}$. Así nos lo cuenta Bosch:

Marcharon también don Agustín Collado, como cirujano, un practicante y el escribano mayor, siendo despedidos por una representación de la ciudad. Terminadas las correspondientes operaciones, regresaron a esta ciudad el 2 de enero de 1804 , siendo recibidos por el Obispo, Corregidor y numeroso acompañamiento en el sitio denominado Molino de Viento. Una vez en la puerta de Triana, se hizo una salva de 15 cañonazos por los castillos de Santa Ana, Mota y una goleta de Guesala. Más tarde, se incorporaron las personas más caracterizadas, tanto eclesiásticas como seglares hasta la casa del Corregidor, donde era tanta la gente presente que apenas se podía caminar por las calles. En el balcón de la casa estaba alojada una orquesta que no acaba de tocar mientras duró la ceremonia ${ }^{39}$.

36 BÉthencourt (1985), p. 290.

37 Chil y Naranjo, G. Estudios climatológicos, manuscrito, pp. 473-475.

38 BÉTHENCOURT (1985), p. 290.

39 Bosch, J. (1967), Historia de la medicina en Gran Canaria, Las Palmas, Cabildo Insular de Las Palmas de Gran Canaria, vol. I, p. 349. 


\section{LANZAROTE}

Las indicaciones del Comandante General surtieron cumplido efecto en el buen ánimo de los lanzaroteños, los cuales colaboraron de buen grado, pues

tenían benéficos sentimientos, gratitud y aprecio por el interés que el Soberano tomaba en su bien..., y discernimiento para comprender que era bueno, cuando en otras nuestras Islas tuvo sus contradicciones, efecto de ideas rancias y tercas ${ }^{40}$.

Una singular obrita de teatro, fechada en Teguise el 16 de marzo de 1804, compuesta por el Dominico Fray Bernardino de Acosta, y titulada La Vacuna o Patriotismo Lanzaroteño, nos proporciona los principales pormenores de lo que ocurrió en esta isla en relación con la vacuna. Así, explica que, con los donativos de varios clérigos, Don Bartolomé de Torres

Teniente de Milicias, siendo aun Alcalde mayor, determinó mandar a cinco Niños a Santa Cruz para traer á esta Ysla la Vacuna, y vencido el primer obstáculo, qual era el de asignar una Cantidad al Facultativo que debía acompañarles (pues este se ofrecio voluntariamente y sin interés alguno) trató de vestirlos, y equiparlos con la mayor decencia, para cuyos costos, y los de mantenimiento en Santa Cruz se le agregaron los Señores Beneficiados Dr. Dn. Antonio Cabrera, y Dn. Domingo de la Cueva, Dn. Josef Fco Comisario del Santo Oficio, Dn. Josef Fco de Armas Ayudante mayor de Milicias, y Dn. Carlos Ramírez y Casañas, quienes con la misma generosidad y Patriotismo han suplido también, todos los de los preparativos del recibimiento ${ }^{41}$.

Y pasa ya a hablarnos del recibimiento de los niños ya de vuelta:

Al alborear del dia, dio fondo en el Puerto de Arrecife el Buque que conducía los Niños vacunados, tiró dos Cañonazos, y otro dos al pasarlos á la Lancha; los que fueron correspondidos con tres, por la Goleta nombrada la Barbara, propia de Dn. Josef de Armas: la misma repitió otros tres ál desembarcar en el Muelle, y el mismo numero ál pasar por la Casa de dicho Señor ${ }^{42}$.

Continúa relatando la calurosa bienvenida e indica cómo fueron vacunados otros niños:

\footnotetext{
40 BÉTHENCOURT (1985), p. 291.

41 RAMírez (2001), pp. 192-198, Nota 2a , p. 194.

42 Ibid., Nota $4^{\text {a }}$, p. 194.
} 
Es digno de elogio el jubilo que manifestaron los vecinos de dicho Puerto, al ver llegar los Niños. Al primer Cañonazo saltaron de sus Camas el Venerable Cura Dn. Francisco Acosta, el Alcalde Real Dn. Lorenzo Cabrera, el Gobernador Dn. Luis Cabrera, el Subteniente Dn. Josef de Armas, Dn. Manuel Alvarez, Dn. Josef del Castillo, y otros muchos sugetos de los principales, y mandaron una Falua para desembarcarlos, esperando en las primeras gradas del Muelle, acompañados de un número tan grande del Pueblo, que lo ocupaba en toda su longitud. Alli los recibieron en sus brazos, hasta la Carroza, que para este obgeto había hecho y adornado el referido Dn. Josef de Armas, en la qual pasaron con tan lucido acompañamiento á la Parroquia, y habiéndose cantado un Te Deum, solemne, fueron llebados á la Casa que les tenían preparada y adornada con la mayor decencia... A las siete de la noche se vacunaron por el Dr. Dn. Pedro Suarez, cinco niños, lo que se celebró con un cañonazo por la referida Goleta la Barbara, y al siguiente dia se hizo la misma operación en otros tres ${ }^{43}$.

Unos días más tarde, los niños fueron llevados a Teguise, la capital de la Isla donde, después de una misa solemne en la parroquia y el canto del $T e$ Deum, se vacunó a más niños:

Quando llegaron los Niños á la Plaza de Santo Domingo, que está en la entrada de la Capital, fueron saludados por el Castillo de Santa Bárbara con cinco cañonazos (...), el Ayuntamiento, el Clero, el Gobernador de las Armas Coronel Dn. Francisco Guerra, con toda la oficialidad que habia convocado para este efecto, y las comunidades religiosas, salieron á recibirlos á la vista de un numeroso concurso del Pueblo, que ocupaba toda la Plaza, y Azoteas... A esto siguió la Vacunación de cinco niños, saludando á cada una de estas operaciones seis violentos que estaban situados al frente de dicha Casa, con lo que se concluyó la función, acompañando todos ál Ayuntamiento hasta la Casa del Alcalde mayor ${ }^{44}$.

Finalmente, Fray Bernardino reconoce la inestimable tarea realizada por los médicos:

No olvidaremos el merito que hán contrahido con la Patria, y humanidad los Señores Dn. Pedro Suarez y Dn. Cristóbal de la Cueba. El primero aunque no es patricio há querido dar prueba del desinteres con que debe exercer su facultad todo buen Profesor de Medicina quando se trata de socorrer a la humanidad, y del amor que yá profesa á estos naturales que le han elegido por su Medico Titular; y el segundo porque conociendo la fuerza de los Vinculos que le unen con la Patria, abandonó sus propios intereses en un estado que a qualquiera otro hubiera hecho

43 Ibid., Nota $5^{\text {a }}$, pp. $194-195$
$44 \quad$ Ibid., Nota $8^{\text {a }}$, pp. $195-197$ 
desmayar. Excitados por tan nobles sentimientos se ofrecieron á acompañar los Niños, y lo executaron hasta su retorno conservando el fluido vacuno á pesar de las indispensables contrariedades que ofrecen los viages en la estacion presente ${ }^{45}$.

\section{LA PALMA}

\section{Nos cuenta Don Juan Primo de la Guerra gráficamente que}

desde el 6 del corriente salió de Santa Cruz la expedición de la vacuna. Su primer destino es la isla de Puerto Rico. Después han llegado a Santa Cruz algunos niños enviados de la isla de La Palma para la inoculación de la vacuna. Se dice que damas de aquella ciudad [Santa Cruz de La Palma] se esmeraron en adornarlos; que traen gorras, bordadas en ellas las armas de la isla y que han sido muy bien recibidos. Los niños vacunados por los profesores de la expedición han pasado la erupción felizmente ${ }^{46}$.

\section{¿Qué es lo que ocurrió en la isla bonita para que se diera tal retraso? Por- que en Santa Cruz el Síndico Personero Don Esteban Martín Pintado había redactado un informe sobre las medidas que debían tomarse:}

Que supuesto que a este fin deben pasar algunos niños a la villa de Santa Cruz de Tenerife, y que allí se halle dispuesto alojamiento para los inoculados que serán asistidos a expensas de S. M., que todos concurran a persuadir a los padres de que proporcionen a sus hijos un bien tan conocido. Que los niños, que la Junta de Caridad ofrezca, servirán de ejemplo a otros. Que el Cabildo debe nombrar uno de los dos facultativos titulares de esta ciudad para que pase a Santa Cruz de Tenerife a instruirse prácticamente de la operación de la vacuna y pueda después dirigirla aquí con el conocimiento debido. Que se nombre una persona que se encargue del cuidado de los niños y que además tenga aptitud para aprender a inocular, a fin de que después pueda hacerlo en los pueblos de esta isla. Que se flete un barco para el retorno de los niños a fin de que puedan llegar aquí con la vacuna en sazón para poderla trasmitir a otros. Que ocasionándose con esto algunos gastos y no teniendo el Cabildo facultades para disponer de los sobrantes de Propios, se recurra al Sr. Regente de la Audiencia por la correspondiente licencia, y en el ínterin que se extraiga la cantidad necesaria ${ }^{47}$.

$45 \quad$ Ibid., Nota $10^{\mathrm{a}}$, p. 197.

46 PRIMO (1976), pp. 227-228 (Domingo, 15 de enero de 1804).

47 Toledo, F. y HernÁndez, M. (2001), Historia de la medicina palmera y sus protagonistas, La Laguna, Centro de la Cultura Popular Canaria, p. 216. 


\section{Recibido el informe, el Cabildo}

acordó nombrar al cirujano revalidado y titular de esta isla don Matías de Sáseta para pasar a Santa Cruz con el objeto indicado, y se comunicó al Síndico para que puesto de acuerdo con los individuos de la Junta de Caridad designase el número de niños expósitos que se debían de mandar ${ }^{48}$.

El Sr. Regidor Don José Sánchez se ofreció a ir voluntariamente a acompañar y cuidar a los niños que el Sr. Alcalde mayor eligiese además de los expósitos, y el Ayuntamiento volvió a acordar:

Que para los gastos se tomarán del arca 200 pesos hasta tanto que se recibiese la licencia del Sr. Regente, a saber: 100 pesos para el médico y 100 para el gasto de los niños. Que cuando éstos retornasen, se recibieran como un extraordinario beneficio que la providencia nos dispensa, pasando al muelle este Ayuntamiento acompañado de todos los Cuerpos y personas visibles, de donde trasladados a la Iglesia parroquial se cantase en ella el Te Deum ${ }^{49}$.

El retraso de la llegada de los niños palmeros a Tenerife obedeció a la desconfianza y el recelo de la población, por lo que el Beneficiado de la Iglesia de El Salvador, Don Manuel Díaz, icono de la clerecía palmera ilustrada, consiguió que desistiesen de sus dudas merced a la homilía que dictó el 1 de enero de 1804 durante la misa ${ }^{50}$.

Casa-Cagigal escribió una interesante carta a Don Manuel Díaz con motivo de este sermón, uno de cuyos párrafos reza así:

Con particularísimo gusto he leído el exhorto con que usted anunció a su pueblo el día 1 de este mes el bien inmenso de la vacuna. Dar al César lo que es del César y saber unir los sagrados intereses de nuestra religión santa con los respetables del orden social, es mucho sin duda, para canonizarlos, digámoslo así, con aquella elocuencia sagrada que a la unción de los Agustines y los Ambrosios une la brillantez y la valentía de los Demóstenes y los Tácitos, es apurar todo lo sublime del ministerio sacerdotal... ${ }^{51}$

Por último, también Don Juan Primo de la Guerra se hace eco del exhorto de Don Manuel Díaz:

48 Ibidem

49 Ibid., pp. 216-217.

50 Vid. el texto en el apéndice documental.

51 TOlEDO y HERNÁNDEZ (2001), pp. 217-218. 
He visto un exhorto del beneficiado de la ciudad de La Palma animando a sus feligreses para que enviasen a Tenerife los niños para recibir el beneficio de la vacunación, el cual parece formado sobre ideas exactas e ilustradas, que hacen honor a aquel eclesiástico. El comandante general, constante en la protección y fomento de la inoculación de la vacuna, ha establecido en la plaza de Santa Cruz una casa destinada a suministrar al público este preservativo. No estoy impuesto en su régimen ni en los fondos destinados a su subsistencia. También he oído que el profesor don Domingo Saviñón ha escrito un plan en que propone algunos medios para la conservación de la vacuna en la provincia de Canarias ${ }^{52}$.

\section{CONCLUSIÓN}

De todo lo dicho hasta ahora bien puede colegirse que la estadía de la Real Expedición Filantrópica de la Vacuna en nuestro Archipiélago cumplió sus objetivos. Canarias fue el auténtico banco de pruebas de la Real Expedición. Además, la experiencia adquirida en Canarias fue de gran utilidad a la hora de afrontar los diversos problemas en las siguientes escalas. Prueba de ello es el texto que introduce la Real Cédula del 26 de enero de 1805, en la que se expide un reglamento para generalizar la inoculación de la vacuna, tal como se hizo en Canarias:

Excitado el amor paternal del Sr. D. Carlos IV hácia sus vasallos con el egemplo de lo que se había hecho en Canarias al arribo de la expedición maritima, destinada á propagar en los dominios de Indias el admirable descubrimiento de la vacuna, é informado de que el fluido se extingue y pervierte confiando su conservación al cuidado solo de los facultativos que lo manejan, tuvo á bien resolver que en todos los hospitales de las capitales de España se destinase una sala para conservarlo y comunicarlo á cuantos concurriesen á disfrutar de este beneficio, y gratuitamente a los pobres, practicando las operaciones por tandas periódicamente $\mathrm{y}$ en corto número de personas proporcionado al de los que naciesen de ordinario en cada capital. Para que tuviesen cumplido y pronto efecto sus soberanas intenciones sobre tan importante asunto, se previno de Real órden á la Junta superior de Cirugía, cuando no se habia creado aun la superior gubernativa de Medicina, que se propusiese el correspondiente reglamento, teniendo presente y adoptando del formato para Canarias lo que fuese mas análogo á la península ${ }^{53}$.

52 PRimo (1976), p. 228 (Sábado, 28 de enero de 1804).

53 Real Cédula de 26 de enero de 1805 . Tomado de BALAguer y BALlester (2003), fig. 8, p. 9. 
La estancia de la Real Expedición en el Archipiélago Canario dejó una gran huella y no sólo en los aspectos relacionados con la higiene pública, sino también en otros, que podríamos llamar sociológicos. Así, aun habiendo partido ya la expedición vacunal, todavía se celebró una conmemoración de su venida en la villa de La Orotava. Nos lo cuenta el propio Don Juan Primo de la Guerra:

Dícese que en la villa de La Orotava espérase una función de iglesia en acción de gracias por la vacuna y que los caballeros de aquel pueblo tratan de tener una reunión social para celebrar este beneficio de Dios y del rey ${ }^{54}$.

Y concluye más adelante reseñando la propia celebración:

El Domingo 5 del corriente se verificó en la villa de La Orotava la función de aquellos caballeros en celebración de la vacuna. Tuvieron la música del batallón de Canarias; de La Laguna fueron también algunas personas y la concurrencia fue en la casa donde murió don Francisco Benítez, en frente del Colegio ${ }^{55}$.

Pero no todo fueron parabienes. El escribano del Puerto de la Cruz José Álvarez Ledesma se convirtió en un enemigo declarado de la vacuna, pues estimaba que el proceso no sólo contravenía las leyes de la Naturaleza sino la voluntad de Dios y el orden sobrenatural, pues vacunar suponía resistir la voluntad del supremo Hacedor. Sabemos, sin embargo, que rectificó más adelante, vacunando a alguno de sus hijos en el brote de $1828^{56}$.

54 Primo (1976), p. 229 (Viernes, 3 de febrero de 1804).

55 Ibid., p. 229 (Miércoles, 15 de febrero de 1804). Cf. LuQue, A. (1998), La Orotava, corazón de Tenerife, La Orotava, Ayuntamiento, p. 212.

56 BÉthenCOURT (1985), p. 295. Cf. Álvarez de Ledesma, J. Discurso sobre la vacuna descubierta y recomendada, manuscrito, Biblioteca Municipal de Santa Cruz de Tenerife. 


\section{APÉNDICE DOCUMENTAL}

Exhorto hecho al pueblo el $1^{\circ}$ de enero de 1804 por el beneficiado don Manuel Díaz, en su parroquia del Salvador de la Ciudad de La Palma, con motivo de la vacuna [PRIMO DE LA GUERRA, J. (1976), Diario II, 1808-1810, Madrid, Aula de Cultura de Tenerife, pp. 242-244].

Mis amados hermanos: no miréis como una cosa extraña y ajena de nuestro ministerio el asunto particular de que vengo a hablaros. El interés de los pueblos es también el de sus pastores, y desgraciados de aquellos que miran con indiferencia los medios saludables con que se pueden evitar las calamidades públicas.

Penetrado de estos justos sentimientos, yo os vengo a anunciar que la Divina Providencia, de cuya voluntad absoluta pende exclusivamente la ilustración del entendimiento humano, se ha compadecido en fin de los estragos espantosos que por tantos siglos ha causado sobre la Tierra el azote terrible de las viruelas y que ha inspirado a los hombres un medio tan sencillo como eficaz para evitarlo. No soy el primero que se ha valido del sagrado ministerio de la predicación para dar a los hombres esta noticia saludable. La Europa respeta la memoria del párroco de Brum en Gebing, pueblo inmediato a Viena, que anunció a sus feligreses este admirable descubrimiento y les persuadió su práctica. En Ginebra se han valido del mismo medio para instruir a los pueblos en un objeto tan importante y la Francia le ha adoptado también, después de haber asegurado sus sabios que este nuevo descubrimiento tenía toda la certeza necesaria para que los ministros del Culto le anunciasen y persuadiesen a sus pueblos. Así yo no hago más que unir mi débil voz a la de tantos párrocos amantes de la humanidad y deciros que no desperdiciéis, ni aun miréis con indiferencia un beneficio tan particular, que no puede venir de otra mano que de la del Padre de Misericordia.

Acordaos, mis amados parroquianos, de aquellos días de horror y de tristeza, de aquellos años de 1787 y 88 en los que el funesto contagio de las viruelas nos arrebató una parte muy considerable de nuestros conciudadanos y en los cuales, no sólo las madres vieron a sus tiernos hijos pasar en un instante de sus dulces brazos a los de la muerte, sino también las esposas a sus amados esposos y éstos a aquéllas, muchas veces con el fruto de sus entrañas. Acordémonos de aquellos días de luto y consternación general y hagamos por no presenciar otra vez, ni que presencien jamás nuestros descendientes, una escena tan lastimosa. Hagamos venir a la isla y propagar en ellas la vacunación, beneficio admirable que la Providencia nos ha concedido y que, según el voto unánime de todas las naciones cultas, es una operación maravillosa y un fenómeno extraordinario por medio del cual se pone en el hombre sin el menor peligro un preservativo eficaz contra aquel contagio, que tantas veces ha llenado los sepulcros.

Un descubrimiento tan feliz merecería, sin duda, la empresa de ir a lo último de la Tierra, a buscar este precioso antídoto y mostrar nuestro reconocimiento a aquellos hombres que han trabajado en descubrirle y propagarle, pero nuestro piadoso Monarca ha prevenido nuestros deseos de modo sabio y generoso. Ha formado una expedición marítima, compuesta de profesores hábiles y tiernos niños que lleven por todos sus dominios 
este fluido bienhechor: ¡Conquistadores de la Tierra, hombres feroces e inhumanos que habéis formado tantas expediciones sangrientas con el fin de adquirir en la Historia un nombre ilustre, los humanos harán odiosa a las generaciones futuras vuestra memoria, al paso que honrará a Carlos IV por una expedición pacífica y bienhechora, cuyos primeros héroes son veintidós inocentes que llevan sucesivamente en sus brazos no el hierro destructor, de que no son capaces, sino el consuelo y alivio de la Humanidad!

Esta interesante expedición ha llegado ya al Puerto y Villa de Santa Cruz, donde fue recibida con todas aquellas demostraciones de amor que las almas sensibles tributan sin esfuerzo a la beneficencia y todo el primer Jefe de esta Provincia se ha llenado de un piadoso entusiasmo y, como ha expresado su corazón noble y generoso, ha llevado en sus brazos al primero de aquellos inocentes que llegó a tierra, llevándole en ellos hasta su casa. También ha convidado al Ilustre Ayuntamiento de esta Isla para que envíe niños que reciban en aquel puerto tesoro inestimable que deberán repartir en todos nuestros pueblos.

Mis hermanos, a un Jefe tan celoso de nuestro bien, llamémosle el amigo de los isleños, que su alma grande y benéfica entienda muy bien esta expresión de nuestro reconocimiento, pero por más justos que sean aquí los elogios y demostraciones de gratitud, no gastemos en ellos tan preciosos momentos: las almas generosas sólo quedan compensadas cuando se reducen a la práctica sus intenciones benéficas. Prudentes y celosos Magistrados, llevad pues a su debido efecto vuestros proyectos de patriotismo, sin perdonar los medios que sean necesarios para conseguir un tan deseado fin.

Ministros del Santuario, empleemos todo nuestro celo en desterrar las preocupaciones que la ignorancia o la malicia puedan presentar en nuestros pueblos al beneficio singular de la Providencia. Acordémonos que Jesucristo, pudiendo autorizar su misión divina con señales maravillosas en el Cielo, como lo pedían los judíos carnales, prefirió autorizarla con señales de bondad y compasión sobre los hombres mismos curando milagrosamente sus enfermedades. Acordémonos que del mismo modo autorizaron su misión los Apóstoles que le sucedieron en la propagación del Evangelio y que si nosotros, después del establecimiento de la Iglesia, no tenemos necesidad de los prodigios para autorizar la nuestra, debemos hacerlo con ejemplos de humanidad. ¿Y se nos puede presentar, acaso, una ocasión más oportuna para dar un testimonio auténtico de que somos ministros de una Religión cuyos caracteres de humanidad y beneficencia le dan una prueba ilustre de su verdad? ¡Dichosos nosotros si podemos, con nuestro celo y caridad, ahorrar a las generaciones futuras las lágrimas que las presentes han derramado a causa de aquel terrible contagio!

Tiernas y amorosas madres, padres cariñosos, no dudéis un instante del beneficio que la Providencia nos dispensa por manos de nuestros Soberanos. No deis oídos a los ignorantes y preocupados que siempre levantan el grito contra cuanto no conocen. Estos son unos hombres inhumanos que, como se vean libres del peligro, les importa poco la existencia de los demás y que con pretextos frívolos, que nada prueban sino su ignorancia y su ninguno interés por la Humanidad, se oponen a que libremos de los brazos de la muerte una multitud de inocentes, que son muy acreedores de toda nuestra compasión. Decidles que no es ésta una inoculación semejante a la que se practicó pocos años en esta Isla que aunque a la verdad tienen sus ventajas, no debe compararse con la vacunación, que ni aun merece el nombre de incomodidad.

No temáis, pues, entregar vuestros hijos para conducirles al Puerto y Villa de Santa Cruz a recibir allí el beneficio de la Providencia. Yo os aseguro que volverán en triunfo a 
hacer de él un presente magnífico a sus padres. No temáis los gastos que esto os pueda ocasionar, que nuestro Monarca lo ha prevenido todo y, según la expresión sublime de nuestro Comandante, «el corazón magnánimo de nuestro Rey no pide otra recompensa de nuestra parte que el que admitamos el beneficio que dispensa».

Y vosotros, hombres generosos y benéficos amantes de la Humanidad y amigos de la Patria, cooperad hasta su logro en una empresa tan digna de vuestras almas sensibles, a fin de que la posteridad no sepa, sino por la Historia, los estragos de aquel funesto contagio que nos ha hecho derramar tantas lágrimas.

Y Vos, Dios benigno y bienhechor, bendecid los días de nuestros Soberanos por su paternal amor hacia nosotros. Recompensad las tareas del primer Jefe de nuestras Islas; las de nuestros Magistrados, las de nuestros amigos. Conceded la prosperidad y la paz a aquellos esposos que han formado el generoso designio de enviar sus tiernos hijos a que nos traigan vuestro precioso beneficio. Velad en fin, Padre bondadoso, sobre estas inocentes criaturas en su navegación, como también sobre aquellos que han traído a nuestras Islas el don de vuestras manos y que van a llevarle a unas tierras muy remotas. Mandad, ¡oh Padre de la Naturaleza! Ordenad a las tempestades que miren como sagrado el bajel que les conduce e imponed silencio al Mar para que el bramido de sus olas no asuste a aquella inocencia bienhechora. Bendecidnos a todos y, si es conveniente a nuestra eterna salvación, concedednos la salud pública, que es el mayor de nuestros beneficios temporales. Amén. 